\title{
A importância do design na viabilização de embalagens para uma micro e pequena empresa da maricultura
}

\author{
Lucas José Garcia \\ Universidade Federal de Santa Catarina \\ lucasjose@gmail.com \\ Daniel Theiss Ristow \\ Universidade Federal de Santa Catarina \\ ristowdaniel@gmail.com \\ Silvia Marcia Fiori Sala \\ Universidade Federal de Santa Catarina \\ silviamfsala@gmail.com \\ Giselle Schmidt Alves Díaz Merino \\ Universidade Federal de Santa Catarina \\ gisellemerino@gmail.com \\ Leila Amaral Gontijo \\ Universidade Federal de Santa Catarina \\ leila.gontijo@ufsc.br \\ Eugenio Andres Díaz Merino \\ Universidade Federal de Santa Catarina \\ eugenio.merino@ufsc.br
}

\begin{abstract}
Resumo: O cultivo de ostras e mexilhões em Santa Catarina é uma importante vertente econômica do estado. O setor enfrenta dificuldades para comercialização, principalmente no que se relaciona ao potencial econômico de pequenas empresas e à ideia do consumidor sobre o produto. Assim, esta pesquisa objetivou desenvolver embalagens para viabilizar a comercialização de produtos de uma Micro e Pequena Empresa do setor da maricultura. Para tanto, foi realizada uma pesquisa aplicada, que utilizou como procedimentos técnicos o levantamento bibliográfico, grupo focal, entrevistas com consumidores e com a empresa. Como suporte à prática projetual, foi utilizado o Guia de Orientação para o Desenvolvimento de Projetos (GODP). Como resultados são apresentadas embalagens para duas linhas de produto: linha gourmet e linha food service. Aponta-se ainda, como o design dentro de uma visão estratégica, denominada gestão de design, pode contribuir para a maricultura e a apresentação de seus produtos ao consumidor.
\end{abstract}


Palavras-chave: Embalagem, Design, Gestão de Design, Maricultura, Mexilhões.

\begin{abstract}
The cultivation of oysters and mussels in Santa Catarina is an important economic activity. The sector faces difficulties in marketing, especially in relation to economic potential of small businesses and the idea of the consumer about the product. Thus, this research aimed to develop packaging to facilitate the marketing of products of a Micro and Small Enterprise of the mariculture industry. For this purpose, an applied research that utilized technical procedures as bibliographic research, focus group and interviews with consumers and the company was done. To support design practice was used the Guide of Orientation to Project Development (GODP). As results is presented packagings for two product lines: line gourmet and line food service. It is also presented as the design within a strategic vision, called design management, can contribute to the mariculture and the presentation of their products to consumers.
\end{abstract}

Keywords: Packaging, Design, Design Management, Mariculture, Mussels.

\title{
1. INTRODUÇÃO
}

A Gestão de Design pode ser uma alternativa viável para potencializar a aceitação e valorização de produtos da aquicultura. Nesse sentido, cabe ao design, dentro de sua visão estratégica, desenvolver propostas que atendam às demandas de consumo, considerando os produtos, produtores e suas características locais de produção. Conforme argumenta Gimeno (2000), as vantagens competitivas do design não são exclusividade das grandes corporações, pequenas empresas também podem ter seus produtos valorizados e inseridos no mercado global.

A aquicultura corresponde ao cultivo de organismos aquáticos e compreende a criação de peixes, crustáceos, moluscos e outros organismos que vivem em rios, lagos, lagoas e oceanos (SEBRAE, 2013). A atividade pode ser dividida entre o cultivo em águas doces e em águas salgadas, sendo a maricultura o cultivo de organismos aquáticos em águas salgadas (SILVEIRA; SILVA, 2011).

Segundo a Organização das Nações Unidas para a Alimentação e a Agricultura (FAO), o crescimento anual da aquicultura a nível mundial corresponde a 8,3\% (FAO, 2010). De acordo com a Empresa de Pesquisa Agropecuária e Extensão Rural de Santa Catarina (EPAGRI), o setor cresce aproximadamente $6,5 \%$ ao ano, configurando-se como o setor de produção de alimentos de origem animal que mais cresce no mundo. Dentro deste contexto, acredita-se que em breve a maior fonte de pescados seja proveniente de cultivos e não de atividades extrativistas e predatórias (SILVEIRA; SILVA, 2011).

No ramo da maricultura, Santa Catarina foi o primeiro estado a inserir políticas públicas e instaurar um processo de legalização de áreas marinhas para finalidade de cultivo de moluscos. Aspectos da legislação ligados à atividade passaram a ser tema de reuniões que buscavam o esclarecimento sobre a importância da regularização de cultivos para o ordenamento do setor (NOVAES et al., 2010). 
Em reflexo a isso, cerca de 1000 famílias, equivalente a 6 mil empregos diretos e indiretos, reforçam a economia do estado com a produção de, em média, 15 milhões de toneladas anuais de mexilhões e ostras (OPORTUNIDADES \& NEGÓCIOS, 2012). A produção total catarinense representa $95 \%$ dos moluscos cultivados no Brasil, sendo que deste montante, $90 \%$ são produzidos na região da Grande Florianópolis, o que leva o país à segunda posição entre os produtores da América Latina (VICENTE, 2010).

A atividade corresponde a uma das grandes vertentes econômicas do estado, destacando-se pela produção de moluscos como mexilhões, ostras e vieiras (SILVEIRA; SILVA, 2011). O destaque da região como polo produtor de moluscos deve-se às características geográficas da região somada ao fomento da Universidade Federal de Santa Catarina (UFSC) por meio do Laboratório de Moluscos Marinhos, à EPAGRI e instituições como UNIVALI, UNISUL e UNIVILLE, bem como empresas, ONGs, associações e cooperativas (OSTRENSKY; BORGHETTI; SOTO, 2007).

Ainda assim, a comercialização dos produtos configura-se como uma fragilidade do setor, pois carece de soluções práticas para a identidade dos produtos, marcas, registros legais, estratégias de divulgação e embalagens. Tais questões relacionam-se diretamente com o design, que adquire espaço nas empresas como uma atividade estratégica, capaz de possibilitar diferenciação e qualidade, aumentando sua competitividade (MERINO, 2010).

Um histórico de estudos e projetos do Núcleo de Gestão de Design da UFSC, iniciados em 2008, como os trabalhos de Garcia e Merino (2008), Garcia e Merino (2009), Dickie, Torres e Merino (2009), Dickie (2010), Merino (2010) e Garcia (2013) relacionaram a Gestão de Design à maricultura, e constataram que o design pode contribuir para o setor ao agregar valor aos produtos, evidenciando suas principais características, sua região produtora e sua responsabilidade como setor sustentável.

Neste contexto, observou-se a oportunidade de realizar esta pesquisa, que tem como objetivo desenvolver embalagens viáveis em baixa tiragem para a comercialização de produtos de uma Micro e Pequena Empresa maricultora.

Apesar do potencial produtivo de Santa Catarina, o cultivo está sujeito aos danos causados pelas variações climáticas, doenças, entre outros fatores que acarretam em dificuldades, prejudicando a produção e a comercialização dos produtos (SEBRAE, 2008). Estes fatos reforçam a importância de se desenvolver ações orientadas a comercialização dos produtos, sobretudo propostas que fortaleçam a confiança do consumidor e sejam economicamente viáveis para os produtores.

No ano de 2013, dois acontecimentos prejudicaram o setor. Inicialmente o cancelamento da Festa Nacional da Ostra e da Cultura Açoriana, evento tradicional de Florianópolis que conta com aproximadamente 45 mil visitantes todos os anos e divulga a tradição no cultivo de moluscos para todo o Brasil. Em seguida a este fato, houve um vazamento de óleo de um transformador do antigo Centro de Treinamento das Centrais Elétricas de Santa Catarina, causando a interdição da prática da maricultura na região, gerando desconfiança no consumidor sobre a qualidade do produto (PMF, 2011; FOLTRAN, 2013).

\section{MATERIAIS E MÉTODOS}

Esta pesquisa classifica-se como aplicada quanto a sua natureza, pois busca a aplicação da gestão de design na maricultura, utilizando-se de corte transversal (GIL, 2008), mais especificamente em uma Micro e Pequena Empresa do setor, localizada 
em Governador Celso Ramos. A pesquisa foi realizada em duas etapas, a primeira descritiva e exploratória e na segunda foi realizada uma aplicação prática (Figura 1).

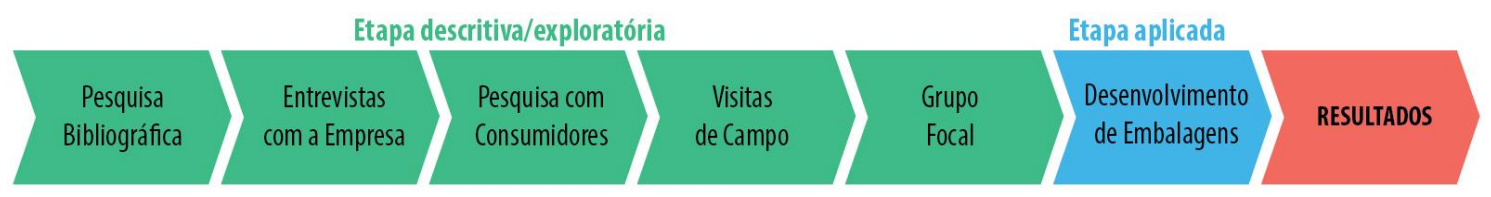

Figura 1: Procedimentos metodológicos adotados na pesquisa. Elaborado pelos autores.

Quanto aos seus objetivos, a pesquisa classifica-se como descritiva aproximando-se da exploratória, pois inicialmente objetivou esclarecer conceitos e ideias de forma ampla - pesquisa descritiva - e em seguida buscou o levantamento de opiniões, crenças e atitudes de uma população, para identificação de possíveis relações entre variáveis - pesquisa exploratória (GIL, 2010). Como procedimentos técnicos foram utilizados: pesquisa bibliográfica, entrevistas realizadas com a empresa, pesquisa com consumidores, visitas de campo e grupo focal com especialistas.

A pesquisa bibliográfica consistiu no levantamento dos quadros local, nacional e mundial do mercado da aquicultura, com foco em oportunidades para pequenas empresas, além de normas e legislação para rotulagem de alimentos.

As entrevistas com a empresa permitiram conhecer seus objetivos, sua realidade, seus parceiros comerciais e o panorama do setor, para que o projeto obtivesse viabilidade técnica e financeira. Para o conhecimento mais aprofundado do público e suas necessidades relativas ao uso do produto e embalagem nos momentos de compra, preparo e armazenamento, aplicou-se um questionário presencial em sete supermercados de Florianópolis, abordando no total 359 consumidores.

Foram realizadas visitas de campo para observação das embalagens de concorrentes nos pontos de venda e posterior análise e identificação da linguagem visual da categoria. Foi realizado também um Grupo Focal com 13 especialistas. Esta etapa auxiliou no enriquecimento do processo criativo, sobretudo na geração de alternativas.

$\mathrm{Na}$ etapa aplicada da pesquisa foram desenvolvidas propostas de embalagens. Como auxílio à prática projetual foi utilizado o Guia de Orientação para o Desenvolvimento de Projetos (Figura 2), desenvolvido pelo NGD/UFSC ${ }^{1}$ para auxiliar no desenvolvimento de projetos de design.

\footnotetext{
${ }^{1}$ O Núcleo de Gestão de Design da Universidade Federal de Santa Catarina é composto por discentes e docentes do curso de design e áreas afins. Tem como foco de suas ações investigar produtos e serviços, e os fatores que influenciam na eficácia e eficiência do design como fator estratégico para organizações. Mais informações podem ser acessadas pelo site: $\underline{\text { www.ngd.ufsc.br. }}$
} 


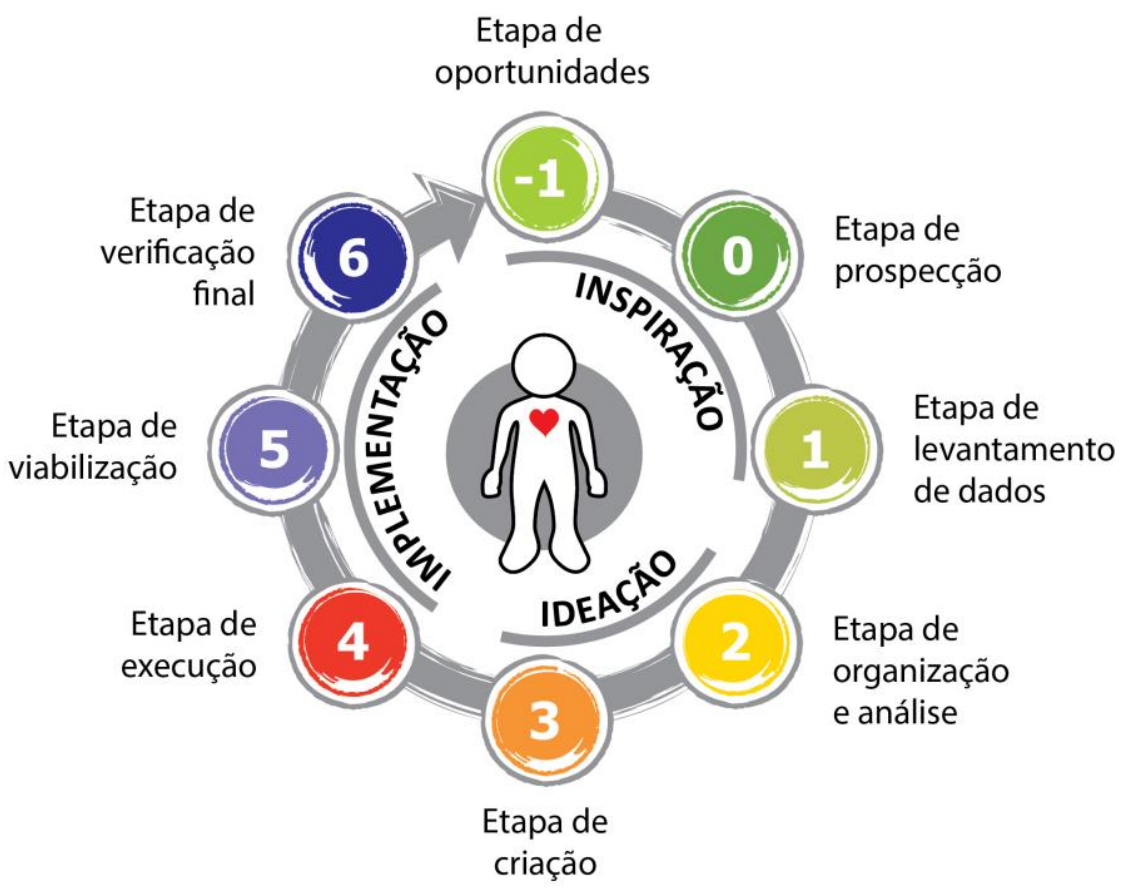

Figura 2: Guia de Orientação para o Desenvolvimento de Projetos. Merino (2013).

Conforme apresentado por Merino, Gontijo e Merino (2011) e Merino (2013), o GODP apresenta um percurso configurado por oito etapas divididas em três momentos: inspiração (etapas -1, 0, 1); ideação (etapas 2, 3) e implementação (etapas 4, 5, 6). A Etapa -1 (Oportunidades), consiste no levantamento de oportunidades de mercado, onde são identificadas possíveis demandas para produtos ou serviços; na Etapa 0 (Prospecção), é definida a demanda ou problemática central que norteará o projeto; na Etapa 1 (Levantamento de dados) é realizado o levantamento de dados em diferentes fontes; a Etapa 2 (Análise de dados) considera a organização e análise dos dados levantados anteriormente, para definição das estratégias de projeto; na Etapa 3 (Criação) são gerados os conceitos e alternativas de projeto a fim de escolher o que melhor responda às especificações e objetivos; na Etapa 4 (Execução) considera-se o ciclo de vida do produto em relação às propostas, ocorrem ajustes e organização da produção; na Etapa 5 (Viabilização) ocorrem verificações e viabilizações da produção, testando o produto/serviço em situações reais, junto a usuários; a Etapa 6 (Verificação), consiste em acompanhar e realizar verificações posteriores a produção, coletando e avaliando impactos. Esta etapa poderá gerar novas oportunidades, realimentando o ciclo.

O guia tem como objetivo sistematizar o processo de design, tornando-o mais consciente e consistente, e vem sendo utilizado e aprimorado em projetos de design do Núcleo de Gestão de Design (NGD/UFSC) e em disciplinas de projeto de design na Universidade Federal de Santa Catarina.

\section{MARICULTURA E DESIGN}

A maricultura tem promovido um avanço tanto social quanto econômico no estado, aumentando a renda familiar de pescadores artesanais, evitando seu êxodo para grandes centros em busca de emprego. O setor promove também o turismo gastronômico, contribuindo para seu reconhecimento como referência nacional na produção de moluscos (SANTOS, 2009). O estado apresenta produção de moluscos 
distribuídos pelos municípios de Florianópolis, São Francisco do Sul, Balneário Camboriú, Itapema, Penha, Governador Celso Ramos, Bombinhas, São José, Palhoça, Biguaçu e Porto Belo, conforme apresentado na Figura 3 (SILVEIRA et al, 2006; SANTOS, 2009).

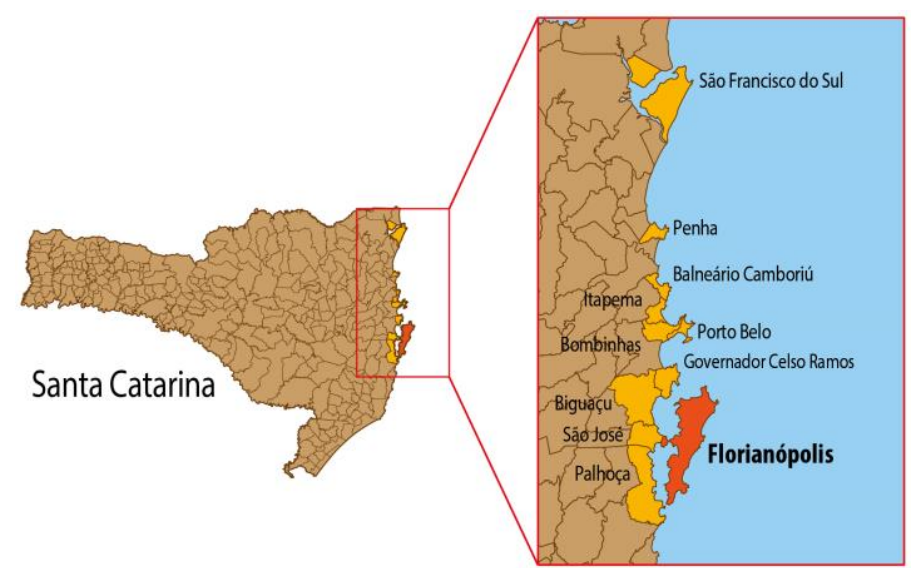

Figura 3 - Principais municípios produtores do litoral catarinense. Elaborado pelos autores.

As pequenas empresas maricultoras, ao atuarem em comunidades locais, viabilizam a produção a nível industrial, promovendo uma cultura de higiene no manejo de alimentos, pois além de atenderem à legislação, estabelecem normas internas que respeitam o âmbito familiar e comunitário da atividade (FAO, 2009).

Conforme apresentado por Pereira et al. (2004), em um número significativo de casos, os produtos de pequenas empresas não apresentam embalagens e rótulos que expressem sua qualidade e características. O design, por meio de um processo sistematizado e consciente de projeto, pode contribuir para minimizar ou eliminar essa realidade melhorando a competitividade dos produtos durante a comercialização.

Outra fragilidade do setor que pode ser sanada pelas contribuições do design está diretamente ligada ao baixo consumo dos moluscos. A classe média é o retrato dessa situação, pois não possui hábito de consumo de moluscos e ainda apresenta desconfiança quanto à segurança alimentar desses produtos (ALTMANN, 2008).

Nesse sentido, cabe ao design incorporar aspectos estéticos, informacionais e legais, para promoção desses produtos no mercado interno, intermediando a comunicação entre produtor e consumidor, criando uma identidade e apresentação para o produto que evidencie sua qualidade, a região produtora, o método sustentável de produção, entre outras características intrínsecas ao produto e as demandas de mercado (ALTMANN, 2008).

Assim, o design posiciona-se de maneira estratégica nas organizações, atuando em seus mercados e problemas, propondo soluções integradas de comunicação e produtos (MARTINS, 2008) desvinculando-se da comum e equivocada ideia de ser uma área exclusivamente estética (BAHIANA, 2004). Diferenciação e qualidade, segundo Gimeno (2000), são atributos que intensificam a competitividade de uma empresa, sobretudo quando associados a um valor final inferior ao da concorrência, ainda que seus custos de produção sejam maiores. $O$ design pode contribuir no equilíbrio entre custo e qualidade, porém, seu êxito depende de sua integração com a gestão da empresa. 


\subsection{Design de Embalagens}

A embalagem possuía inicialmente finalidade de transporte e proteção de alimentos, hoje, as embalagens consistem em um sistema complexo, que informa o consumidor, comunica a marca, promove e vende o produto (NEGRÃO; CAMARGO, 2008). Enquanto a embalagem oferece proteção, acondicionamento e praticidade, o rótulo contém as informações exigidas pela legislação e comunica as características do produto ao consumidor (GARCIA, 2010).

Pereira, Klohn e Silva (2012) explicam que apesar da importância do design em projetos de embalagem, observa-se a ineficiência em relação à legibilidade, leiturabilidade e organização dos elementos. Conforme exposto por Klohn e Pereira (2012), essas questões podem estar relacionadas ao projeto de design dos rótulos de diversos produtos. Dessa forma, algumas informações podem não ser encontradas ou compreendidas pelo consumidor, gerando uma experiência negativa com o produto e consequentemente com a marca. Para Hurley et al (2013), embalagens bem projetadas podem ajudar o produto a superar a concorrência, entretanto, embalagens mal concebidas podem ter impacto negativo sobre a venda e a imagem da marca.

Assim, segundo Garcia (2013), o design de embalagens deve considerar o consumidor, dispondo as informações da embalagem de forma compreensível, organizada e legível; o fabricante, tornando o produto atraente, mesmo com uma elevada quantidade de informações; e o produto, ao projetar embalagens que proporcionem acondicionamento, proteção e transporte adequados, preservando suas características desde a produção até o consumo.

\section{RESULTADOS}

Por se tratar de uma empresa ainda se estabelecendo no mercado, e considerando o seu pequeno porte, um dos requisitos primordiais no projeto foi a preocupação com os custos, que deveriam ser reduzidos, sem prejudicar a qualidade, diferenciação e potencial competitivo da empresa. Além disto, foi priorizado o atendimento das demandas dos consumidores, disponibilizando pequenas porções que incentivam a experimentação (diante do baixo hábito de consumo de mexilhões) evidenciando a praticidade de preparo, conforme identificado na pesquisa de mercado.

O principal produto comercializado pela empresa é o mexilhão e em menor escala ostras e berbigões. Os produtos estão divididos em duas linhas: food service, direcionada a bares, restaurantes e distribuidores; e gourmet, direcionada ao consumidor final. Para os produtos da linha food service, foi especificado o uso de embalagens do tipo saco, devido a seu menor custo de produção. Para a linha gourmet, optou-se por embalagens do tipo bandeja, por apresentar melhor acondicionamento e apresentação do produto no ponto de venda.

Considerando-se o tipo de molusco (ostra, mexilhão e berbigão), a forma de comercialização (fresco, congelado ou resfriado), o tamanho (pequeno, médio ou grande) e o peso (1 quilograma ou 500 gramas) a empresa possui um portfólio com 23 produtos, sendo inviável o investimento no desenvolvimento e produção de embalagens individuais.

Dessa forma, foi criada uma embalagem genérica para o acondicionamento dos produtos. Para sua identificação foi utilizada uma etiqueta, que contém as informações obrigatórias exigidas pela legislação e o conteúdo específico de cada produto, como 
denominação de venda, data de empacotamento, validade, tabela nutricional e lote. As informações são impressas nestas etiquetas com impressora própria da empresa, podendo-se alterar as informações específicas dos produtos.

$\mathrm{Na}$ embalagem de 1 quilograma, a etiqueta com as informações da rotulagem é fixada na parte superior, maximizando a visualização do alimento dentro da embalagem (Figura 4). No entanto, para evitar a reimpressão de um novo lote de embalagens para acondicionamento de porções menores, a parte superior da embalagem pode ser removida com o uso de tesoura, diminuindo seu volume e permitindo o acondicionamento de 500 gramas de produto. Para isso, a etiqueta é fixada sobre parte da área de visualização do alimento.

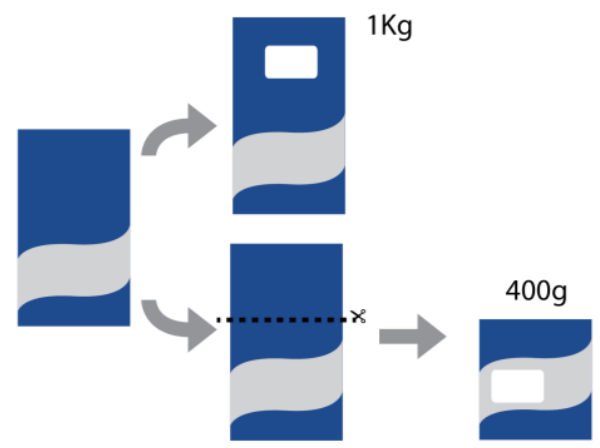

Figura 4: Adaptação da embalagem para porções de 500 gramas. Elaborado pelos autores.

Ainda visando à redução de custos, optou-se por utilizar apenas duas cores nas embalagens: branco e azul. Dessa forma foi possível manter a identidade da empresa e representar seus conceitos na embalagem. Ademais, o uso de cores permitiu diferenciar a embalagem em relação aos concorrentes, que utilizam saco transparente e etiqueta, sem valorizar a apresentação do produto. A seguir, a Figura 5 apresenta alguns produtos da linha food service da empresa, com embalagens de 1 quilograma e 500 gramas.

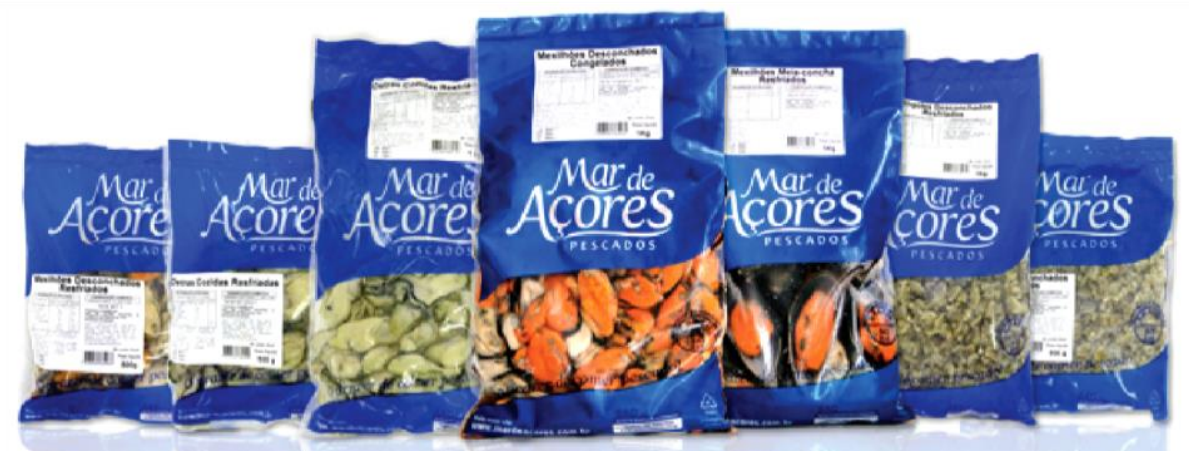

Figura 5: Produtos da linha food service. Elaborado pelos autores.

Embora a área para visualização do produto tenha sido reduzida na versão de 500 gramas, ainda é possível observar o alimento e suas características, sobretudo no verso da embalagem, que não possui impressão, permitindo a análise do produto antes da compra.

Para as embalagens do tipo bandeja (linha gourmet) foi utilizada a mesma estratégia das embalagens do tipo saco (linha food service): embalagens genéricas e etiquetas com as especificações de cada produto. Visando maior apelo de consumo, foi acrescida uma cor, o amarelo. Cabe ressaltar que as bandejas não foram desenvolvidas 
exclusivamente para a empresa, podendo ser adquiridas em pequenas quantidades sem acréscimo de custos, ao contrário das embalagens do tipo saco, que para atingirem viabilidade demandam um pedido mínimo de 30 mil unidades.

Junto à empresa, foram selecionadas bandejas que acondicionem as quantidades desejadas de produto e possuam ao menos uma dimensão igual (para utilização da mesma etiqueta) dessa forma, optou-se por dois tamanhos de bandejas, uma para 150 gramas de produto e outra para 500 gramas. Assim, a bandeja para 150g de produto possui comprimento igual a largura da bandeja para 500g (Figura 6).

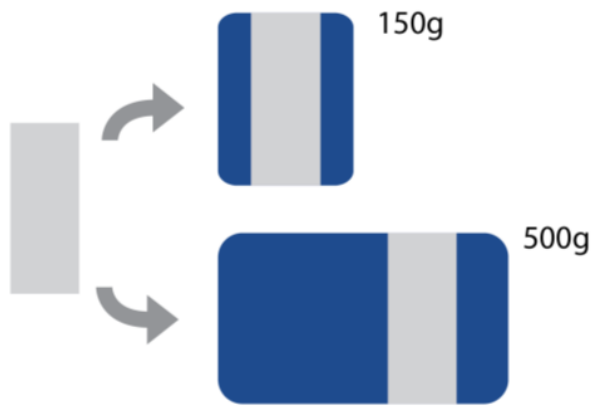

Figura 6: Embalagens diferentes (150 e 500 gramas) com mesma etiqueta para rotulagem. Elaborado pelos autores.

Essa estratégia permitiu a aplicação da mesma configuração visual em diversos produtos da linha, sem limitar a expansão da empresa e reduzindo gastos relativos à rotulagem. O planejamento gráfico desta embalagem atrai atenção do consumidor, oferece unidade visual aos produtos e remete ao planejamento gráfico do website institucional, consolidando e valorizando a identidade da marca, conforme apresentado na figura a seguir (Figura 7).

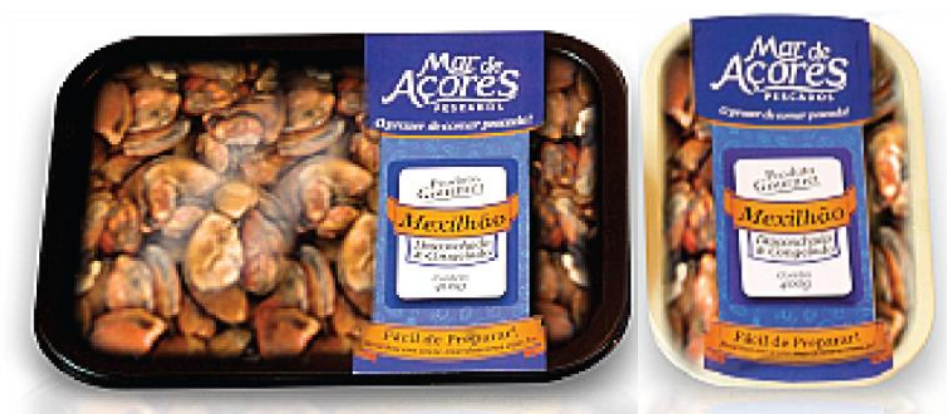

Figura 7: Produtos da linha gourmet. Elaborado pelos autores.

Assim, o mexilhão chega ao consumidor com apresentação comercial distinta, garantia de boas condições de higiene, segurança alimentar e facilidade para o armazenamento, manuseio e preparo, qualidades que valorizam o produto.

\section{CONCLUSÃO}

O contato direto entre a equipe de projeto com empresa e fornecedores possibilitou o atendimento das demandas da empresa em relação a custo, produção de baixa tiragem e variedade de alternativas de uso das embalagens. Esta solução não prejudicou a clareza de informações e unidade visual das embalagens. 
Constatou-se que a Gestão de Design aplicada à maricultura pode contribuir positivamente para a consolidação de micro e pequenas empresas do setor, atendendo às demandas do público-alvo e incentivando o consumo e comércio de mexilhões no mercado catarinense.

O projeto possibilitou a confirmação e atualização de dados já identificados em outros projetos e estudos do NGD/UFSC e estimulou novas possibilidades de estudos na área a partir de aprofundamentos sobre as informações levantadas e materiais desenvolvidos.

Por fim, espera-se que esta pesquisa fortaleça a maricultura, a partir de suas contribuições teórico-práticas, servindo de inspiração para futuros trabalhos que integrem a academia, o mercado e a sociedade.

\section{AGRADECIMENTOS}

À Coordenação de Aperfeiçoamento de Pessoal de Nível Superior (CAPES), ao Conselho Nacional de Desenvolvimento Científico e Tecnológico (CNPq), à Fundação de Amparo à Pesquisa e Inovação do Estado de Santa Catarina (FAPESC), ao Programa de Pós Graduação em Engenharia de Produção (PPGEP/UFSC), ao Programa de PósGraduação em Design e Expressão Gráfica (PPGDEG/UFSC) e a Mar de Açores Pescados por viabilizarem esta pesquisa.

\section{REFERÊNCIAS}

ALTMANN, R; MIOR, L.C.; ZOLDAN, P. Perspectivas para o sistema agroalimentar e o espaço rural de Santa Catarina em 2015: Percepção de representantes de agroindústrias, cooperativas e organizações sociais. Florianópolis: EPAGRI, 2008.

BAHIANA, C. A importância do Design para sua Empresa. Rio de Janeiro: CNI, 2004.

DICKIE, I. B.; TORRES, M. K. L.; MERINO, E. A. D. Inovação social para o desenvolvimento sustentável: ação do óleo reciclado. In: MIG: Revista Científica de Design. Balneário Camboriú: Editora RGF Comunicação e Cultura, abril de 2009.

DICKIE, I. B. Gestão de design aplicada: estratégias de comuicação no contexto do desenvolvimento sustentável. 2010. 173f. Dissertação (Mestrado em Design Gráfico) Programa de Pós-Graduação em Design e Expressão Gráfica, UFSC, Florianópolis, 2010.

FAO. Perspectivas de la agricultura y del desarrollo rural en las Américas: una mirada hacia América Latina y el Caribe - 2009. CEPAL, FAO, IICA - San José. C.R.: IICA, 2009.

FAO. El estado mundial de la pesca y la acuicultura - 2010. Organización de las Naciones Unidas Para la Agricultura y la Alimentación. Departamento de Pesca y Acuicultura de la FAO. Roma, 2010.

FOLTRAN, M. Maricultores tentam encontrar destino para quase um milhão de dúzias de ostras após cancelamento de festa na Capital. Disponível em: $<$ http://diariocatarinense.clicrbs.com.br/sc/geral/noticia/2012/11/maricultorestentam-encontrar-destino-para-quase-um-milhao-de-duzias-de-ostras-aposcancelamento-de-festa-na-capital-3959255.html>. Acesso em: 16 jan 2013.

GARCIA, L. J.; MERINO, E. A. D. A gestão de Design e seu impacto no desenvolvimento de projetos aplicados na área de embalagem e rotulagem da aqüicultura familiar. 
Relatório de Projeto de Pesquisa Parte I CNPq Edital 2007. Florianópolis: Núcleo de Gestão de Design/ Universidade Federal de Santa Catarina, 2008.

GARCIA, L. J.; MERINO, E. A. D. A gestão de Design e seu impacto no desenvolvimento de projetos aplicados na área de embalagem e rotulagem da aquicultura familiar. Relatório de Projeto de Pesquisa Parte II CNPq Edital 2007. Florianópolis: Núcleo de Gestão de Design/ Universidade Federal de Santa Catarina, 2009.

GARCIA, L. J. Manual de rotulagem de alimentos embalados: uma ferramenta de auxílio para designers gráficos. Trabalho de Conclusão de Curso. Universidade Federal de Santa Catarina. Centro de Comunicação e Expressão. Florianópolis, 2010.

GARCIA, L.J. A gestão de design para o desenvolvimento e valorização de produtos da maricultura: uma abordagem de usabilidade. 2013. Dissertação (Mestrado em Design). Programa de Pós-graduação em Design e Expressão Gráfica, UFSC, Florianópolis, 2013.

GIMENO, J.M.I. La gestión del diseño em la empresa. Madrid: McGraw-Hill, 2000.

HURLEY et al. Effects of private and public label packaging on consumer purchase patterns. Packaging Technology and Science. 30 jan. 2013. Disponível em: < http://onlinelibrary.wiley.com/doi/10.1002/pts.2012/pdf >. Acesso em: 16 fev. 2013.

KLOHN, S. C.; PEREIRA, P. Z. Análise de compreensibilidade de pictogramas em embalagens de produtos perigosos. In: 12 Congresso Internacional de Ergonomia e Usabilidade de Interfaces Humano-Tecnologia: produto, informações, ambiente construído e transporte (Anais do Congresso). Natal, agosto de 2012.

MARTINS, R. F. F.; MERINO, E. A. D. A Gestão de design como estratégia organizacional. Londrina: Eduel, 2008.

MERINO, G. S. A. D. A contribuição da gestão de design em grupos produtivos de pequeno porte no setor da maricultura: o caso AMPROSUL. 2010. 146f. Dissertação (Mestrado em Design Gráfico) - Programa de Pós-Graduação em Design e Expressão Gráfica, UFSC, Florianópolis, 2010.

MERINO, G. S. A. D.; GONTIJO, L. A.; MERINO, E. A. D. O percurso do design: no ensino e na prática. In: Moraes, D.; Dias, R. A.; Conselho, R. B. Cadernos de estudos avançados em design: método. Barbacena, MG: EdUEMG, 2011.

MERINO, G. S. A. D. Metodologia para a prática projetual do Design com ênfase no Design Universal. 2013. 130 f. Qualificação Tese (Doutorado) - Curso de Programa de Pós-Graduação em Engenharia de Produção, Universidade Federal de Santa Catarina, Florianópolis, 2013.

NEGRÃO, C.; CAMARGO, E. Design de embalagem: do marketing à produção. São Paulo: Novatec, 2008.

NOVAES et al. Planos locais de desenvolvimento da Maricultura de Santa Catarina. Panorama da Aqüicultura, Florianópolis, v. 20, n. 122, p.52-58, dez. 2010. Disponível em:

<http://cedap.epagri.sc.gov.br/index.php?option=com_docman\&task=cat_view\&gid=1 05\&ltemid=173\&limitstart=5>. Acesso em: ago. 2012.

OPORTUNIDADES \& NEGÓCIOS (Santa Catarina) (Org.). Panorama da Sociedade Catarinense Atual:Agricultura, pecuária e maricultura. Disponível em: 
<http://www.santacatarinabrasil.com.br/pt/agricultura-pecuaria-e-maricultura/>. Acesso em: ago. 2012.

OSTRENSKY, A.; BORGHETTI, J. R.; SOTO, D. Estudo Setorial para consolidação de uma aquicultura sustentável no Brasil. Grupo Integrado de Aquicultura e Estudos Ambientais. Curitiba, 2007.

PEREIRA et al. Valorização de produtos da agricultura familiar através do design. Florianópolis: SAR/Instituto Cepa/SC/Funcitec, 2004.

PEREIRA, P. Z.; KLOHN, S. C.; SILVA, R. P. Análise do design de informação em embalagens de consumo. In: 12을 Congresso Internacional de Ergonomia e Usabilidade de Interfaces Humano-Tecnologia: produto, informações, ambiente construído e transporte (Anais do Congresso). Natal, agosto de 2012.

PMF. Projeto APL das Ostras participa da 26a Fispal Food Service. Prefeitura Municipal de Florianópolis. Disponível em: $<$ http://portal.pmf.sc.gov.br/sites/fenaostra/index.php?pagina=notpagina\&noti=2597 >. Acesso em: 17 jun. 2010.

PMF. Coletiva de imprensa trata dos números finais da FENAOSTRA 2011. Prefeitura Municipal de Florianópolis. Disponível em: <http://www.pmf.sc.gov.br/sites/fenaostra/index.php?pagina=notpagina\&noti=5481> . Acesso em: 21 out. 2011.

SANTOS, A. A. Maricultura (ostras, mexilhões, vieiras e camarões). In: Síntese anual da agricultura de Santa Catarina 2008-2009. Empresa de Pesquisa Agropecuária e Extensão Rural de Santa Catarina. Centro de Socioeconomia e Planejamento Agrícola. EPAGRI/CEPA. Florianópolis, 2009.

SEBRAE. Aquicultura: Saiba mais sobre o cultivo de organismos aquáticos em cativeiro. Disponível em <http://homologacao.sebrae.liberiun.com.br/ setor/aquicultura-epesca/o-setor/ informacoes-gerais/157-9-voce-sabe-o-que-e-aquicultura/BIA_1579>. Acesso em: 14 jan. 13.

SEBRAE. Aquicultura e pesca: Camarões. In: Estudos de mercado SEBRAE/ESPM 2008. Março, 2008.2 Disponível em <www.biblioteca.sebrae.com.br/bds/BDS.nsf/47ACFD29DAFB1D2D832574DC00461D5 4/\$File/NT0003906A.pdf>. Acesso em: jan 2013.

SILVEIRA et al. Desempenho da pesca e da aquicultura. In: Síntese anual da agricultura de Santa Catarina 2005-2006. . Empresa de Pesquisa Agropecuária e Extensão Rural de Santa Catarina. Centro de Socioeconomia e Planejamento Agrícola. EPAGRI/CEPA. Florianópolis, 2006.

SILVEIRA, F. S.; SILVA, F. M. 2011 Desempenho da pesca e aquicultura. In: Síntese Anual da Agricultura de Santa Catarina 2010-2011. Empresa de Pesquisa Agropecuária e Extensão Rural de Santa Catarina. Centro de Socioeconomia e Planejamento Agrícola. EPAGRI/CEPA. Florianópolis, 2011.

VICENTE, A. L. Diagnóstico de problemas e demandas da malacocultura em Santa Catarina: uma visão de maricultores, extensionistas e pesquisadores, Curitiba, 2010. 